\title{
1 Diel growth dynamics in tree stems: linking anatomy and \\ 2 ecophysiology
}

4 Kathy Steppe ${ }^{1, *}$, Frank Sterck ${ }^{2, *}$, Annie Deslauriers ${ }^{3}$

5

$6{ }^{1}$ Laboratory of Plant Ecology, Department of Applied Ecology and Environmental Biology,

7 Faculty of Bioscience Engineering, Ghent University, Coupure links 653, 9000 Gent, Belgium

$8 \quad{ }^{2}$ Forest Ecology and Forest Management Group, Wageningen University, PO Box 47, 6700

9 AA Wageningen, The Netherlands

10 3Département des Sciences Fondamentales, Université du Québec à Chicoutimi, 555

11 boulevard de l'Université, Chicoutimi (QC) Canada G7H 2B1

12

13

14 Corresponding author: Steppe, K. (kathy.steppe@UGent.be)

15

$16 *$ These authors contributed equally to this work

17

18

19

20 Keywords: stem growth, water and carbon relations, stem diameter variations, plant

21 sensors, plant models, trees 


\section{Abstract}

23 Impacts of climate on stem growth in trees are studied in anatomical, 24 ecophysiologial, and ecological disciplines, but an integrative framework to assess

25 those impacts is still lacking. In this opinion article, we argue that three research 26 efforts are required to come up with that integration. First, we need to identify the

27 missing links in diel patterns in stem diameter and stem growth and relate those 28 patterns to the underlying mechanisms that control water and carbon balance.

29 Second, we should focus on the understudied mechanisms responsible for seasonal

30 impacts on such diel patterns. Third, information of stem anatomy and ecophysiology

31 should be integrated in the same experiments and mechanistic plant growth models

32 to catch diel and seasonal scales.

34 Tree stem growth has huge implications but is poorly understood

35 Forests cover $30 \%$ of the earth's land surface, store $45 \%$ of terrestrial carbon, and are

36 responsible for $50 \%$ of the terrestrial net primary production [1, 2]. Forest productivity has

37 increased globally over the past decades, which has been attributed to the positive effect of

38 increasing $\mathrm{CO}_{2}$ on tree growth, thus far offsetting negative impacts of warming and drought

$39[3,4]$. However, the long-term impacts on trees and forests of increasing $\mathrm{CO}_{2}$, rising 40 temperatures, and drought remain highly uncertain [5-7]. Another uncertainty is the role of

41 trees in mitigating rising ambient $\mathrm{CO}_{2}[8]$ and global warming by sequestering carbon in

42 stems [1, 2]. We argue that such ecological uncertainties can only be tackled by developing 43 an understanding of stem growth of individual trees that is based on underlying anatomical 
44 and ecophysiological principles, which are currently represented by separate scientific 45 domains.

46 In this opinion article, we briefly present an overview of the major fluxes and pools 47 of water and carbon inside a stem segment of a tree. We then examine the diel dynamics in 48 radial stem growth and underlying water and carbon mechanisms under wet and dry 49 conditions. We also elucidate the possible processes affecting stem growth across a wet and 50 dry growing season, integrating seasonal trends in stem anatomy and ecophysiology. We

51 distinguish between major known patterns and processes, and more speculative ones. All

52 these discussions are based on observations in the different research disciplines, but also 53 result from mechanistic plant models aiming at integration. Based on this, we show the 54 missing pieces that are critical to building an integrative theory to understand the causes

55 and consequences of tree stem growth on diel and seasonal scales. Addressing the key 56 missing pieces of information is very much needed in order to understand and predict the 57 impacts of a changing climate on annual tree growth patterns and the future production 58 and carbon sequestration potential of forests.

\section{Carbon and water fluxes in stem segments}

61 Water is transported upward in the sapwood, downward in the phloem, radially between 62 sapwood and phloem, and is stored in both sapwood and phloem (Figure 1, fluxes/pools 63 steps 1-4). Carbon is transported downward in the phloem in the form of sugars (Figure 1, 64 step 2), and those sugars are used for maintenance of living cells in sapwood, cambium and 65 phloem (Figure 1, step 6), for growth in the cambium and developing cells (Figure 1, step 66 5), or for storage in the form of starch (Figure 1, step 11). Some carbon released as $\mathrm{CO}_{2}$ by 
67 respiring cells in the tree stem diffuses directly into the atmosphere (Figure 1, steps $7 \mathrm{a}, \mathrm{b}$,

68 and c), whereas another substantial portion of this respired $\mathrm{CO}_{2}$ remains inside the stem

69 (Figure 1, steps $8 \mathrm{a}, \mathrm{b}$, and c) where it dissolves in xylem sap and is transported away from

70 the site of origin (Figure 1, step 7d). Some $\mathrm{CO}_{2}$ slowly diffuses in the axial direction (Figure

71 1, step 9). The amount of $\mathrm{CO}_{2}$ escaping into the atmosphere (measured efflux, Figure 1) is

72 further reduced when respired $\mathrm{CO}_{2}$ is refixed in sugars through photosynthesis within the

73 stem (Figure 1, step 10). Below we discuss diel patterns in these water and carbon fluxes

74 and their consequences for stem growth (see also Figure 2), and we provide an overview of

75 the current state of art technology and methods used to quantify these fluxes (Figure 1, Box

761 and 2).

77

\section{Stem dynamics in water fluxes and storage}

79 Large forest trees lose up to $98 \%$ of their acquired water through leaf transpiration, 80 whereas less than $2 \%$ is used for photosynthesis [9]. On a sunny summer day, an adult tree

81 may lose and acquire several hundred liters of water. Leaf transpiration typically starts

82 minutes to hours earlier than water flow in stem and roots, because transpiration is also

83 supported by water from internal water storage [10]. The daily amount of water withdrawn

84 from storage contributes $5-22 \%$ to the total daily water loss [11-13], and its diel dynamics

85 affect radial stem growth. The typical diel patterns in water relations at the stem level for a

86 fully exposed canopy tree during a sunny day, after a wet period (unstressed conditions

87 with ample soil water reserves), and a dry period are shown in Figure 2. We distinguish

88 between well-established patterns and more speculative patterns in green and red, 89 respectively. 
On a sunny day in unstressed conditions, a strong symmetric hump-shaped pattern

91 of sap flow in the tree stem is observed (Figure 2B), leading to large day/night differences

92 in water potential, and changes in internally stored water in xylem and phloem (Figure 2C).

93 Embolisms in the xylem [14], which can be detected by acoustic emissions (Figure 2B),

94 occur in concert with the decrease in stem water potential and reduce xylem hydraulic

95 conductivity. The embolisms also release water into the transpiration stream, and can thus

96 be considered as a source of storage water or capacitive discharge, damping the amplitude

97 of diel fluctuations in xylem tension [15-18]. Recovery of hydraulic conductivity and

98 overnight refilling of conduits under wet conditions is thought to be possible, but open

99 questions remain $[19,20]$. Although trees can utilize osmotic adjustment to maintain turgor

100 in their living cells [21], mechanistic plant models and supporting observations [22, 23]

101 indicate that water flows from living cells to xylem conduits when xylem water potential is

102 reduced when leaf transpiration exceeds root water uptake. As a consequence, cell turgor

103 (Figure 2D) follows the same decreasing trend as stem water potential, which results in

104 stem shrinkage (Figure 2A) rather than cell expansion and growth during daytime hours

105 [24]. Later in the afternoon, cell turgor, cell expansion and, hence, stem growth resume

106 because of rising stem water potentials, which allows water to flow from xylem conduits

107 into the living cells of the stem. These observations show that diel patterns in growth are

108 not directly driven by carbon limitations - with photosynthesis and phloem loading peaking

109 during daytime hours - but are rather influenced by the turgor pressure in living cells,

110 which coincides with the availability of sugars for growth [25]. More precisely, the

111 difference between the turgor pressure and a wall-yielding threshold value (Figure 2D)

112 determines irreversible cell expansion [24, 26]. This threshold value is estimated to be 
113 around 0.9 MPa [26] for woody tissue, below which the cell cannot expand further [27, 28].

114 Because highest turgor values are established after sunset, highest rates of structural stem

115 growth occur during the night (Figure 2A).

116 These patterns change during a moderately dry period (Figure 2) and even more

117 dramatically during a persisting dry period (e.g. [29]). Because the soil is no longer fully

118 hydrated, soil and stem water potentials are lower, and water storage pools in the phloem

119 and the xylem are no longer fully replenished overnight (Figure 2C). Under these

120 conditions, internal stem water storage pools are depleted, which causes an even more

121 pronounced stem shrinkage during the day (Figure 2A) and more acoustic emissions linked

122 to more embolism formation (Figure 2B). The predicted turgor (Figure 2D) is reduced,

123 following the stem water potential. Once dropping below the wall-yielding threshold value,

124 turgor limits cell expansion and growth (Figure 2A), even during the night. While soil

125 drying continues, most patterns are asymmetric which implies a whole cascade of

126 consequences: more embolism formation in the xylem, resulting in a decreased hydraulic

127 conductivity, stem water potential, turgor pressure and storage of water. Under long 128 persisting droughts, the trends may become irreversible: leaves may wilt and be dropped

$129[29]$ and trees may eventually die [30, 31].

130 We conclude that the qualitative trends in diel water relationships are relatively well

131 studied and understood. There are nevertheless several open questions about how to link

132 embolism repair to underlying mechanisms, the role of turgor and internal water storage in

133 diel trends of stem growth, and the generality of the turgor threshold value across tree

134 species. Another challenge is to better understand why the presented qualitative trends

135 shown in Figure 2, differ so much quantitatively across species. 


\section{Stem dynamics in carbon fluxes and storage}

138 Diel patterns in fluxes, use and storage in tree stems are much less well understood for

139 carbon than for water (Figure 2), even in unstressed conditions with ample soil water

140 reserves. Besides water, radial stem growth depends on carbon as structural material for

141 the formation of new tissue and as source for metabolic energy [32]. The carbon that is

142 locally used for both processes may come from four sources, recently fixed sugars that are

143 transported in the phloem, transitory leaf starch stored during the day and broken down

144 during the night, local stem starch reserves, or locally refixed $\mathrm{CO}_{2}$ in photosynthetic tissue

145 of the stem (Figure 1). Unraveling the much-needed carbon-related mechanism underlying

146 radial growth requires concurrent measurements of photosynthesis, and the fluxes of

147 recently produced photosynthate to respiration, growth and storage as well as the flux of

148 nonstructural carbohydrates out of storage pools. Tracking variations in stem diameter

149 with dendrometers (Figure 1, Box 1) shows promise to quantify growth, but needs

150 mechanistic plant models to unambiguously interpret the signal and separate structural

151 stem growth from reversible stem diameter fluctuations (Figure 2A). In addition to the

152 impact of turgor on cell wall expansion, as discussed above, turgor (rather than water

153 potential) affects cell formation, and deposition and assembly of new wall material [33-36].

154 We therefore speculate that all growth processes (cell expansion, structural growth and its

155 specific energy requirement) mainly occur during the nighttime, in concert with an

156 improved water status and thus favorable turgor [32, 37, 38]. Turgor pressure thresholds

157 for these different processes remain to be explored. 
Another key challenge in understanding stem growth is to quantify diel patterns in

159 respiration. Respiration is often estimated from measurements of $\mathrm{CO}_{2}$ emitted to the

160 atmosphere from the bark surface (Figure 1, Box 2), however this $\mathrm{CO}_{2}$ efflux (Figure 2F)

161 actually reflects the net result of multiple processes, including local growth and

162 maintenance respiration, woody tissue photosynthesis, maintenance of ion transport over

163 cell membranes, decomposition in heartwood, and $\mathrm{CO}_{2}$ originating from respiration in

164 lower stem or root tissues (Figure 1) $[39,40]$. The measured diel pattern may follow the

165 hump-shaped trend as expected from the exponential relationship between respiration and

166 temperature [41], but daytime depressions in net $\mathrm{CO}_{2}$ efflux may occur (Figure $2 \mathrm{~F}$ ), because

167 of $\mathrm{CO}_{2}$ transport in the xylem with the transpiration stream, or restricted growth during the

168 daytime due to the loss of turgor in the living tissues [37]. A tight coupling has been

169 observed between stem $\mathrm{CO}_{2}$ efflux and $\mathrm{CO}_{2}$ dissolved in xylem sap (Figure 2F) [39], and this

170 relationship has been used to quantify the resistance to radial $\mathrm{CO}_{2}$ diffusion [42]. Some

171 indication exists that $\mathrm{CO}_{2}$ does not only diffuse radially, but may also slowly diffuse axially

172 along air-filled spaces in the wood [43]. Multiple processes, both locally in the considered

173 stem section and remotely in other tree parts, thus drive the $\mathrm{CO}_{2}$ emitted by a stem

174 segment, but quantifying their relative importance remains a challenge. Stem anatomy

175 likely influences the resistance to radial $\mathrm{CO}_{2}$ diffusion, as well as local respiration and sap

176 flow rates, in turn affecting net $\mathrm{CO}_{2}$ efflux and the amount of $\mathrm{CO}_{2}$ retained in the xylem [39,

177 40]. Investigating stem anatomy, including bark thickness and tree hydraulics, may help to

178 explain the large variations observed in net $\mathrm{CO}_{2}$ efflux, and contribute to a clearer

179 understanding of stem respiration [40, 42]. 
181 skeletons in the cell structure, and thus requires information on sugar concentrations in the 182 stem. Although critical, predictions of dynamics in sugar concentration in xylem, phloem 183 and cambium are highly uncertain (Figure 2E), and so are the relative contributions of the 184 different sugar sources (from leaves, stem starch reserves, or local woody tissue 185 photosynthesis) driving those dynamics. Sugars originating from recent leaf photosynthesis

$186[32,44]$, woody tissue photosynthesis refixing respired $\mathrm{CO}_{2}$ in stem chloroplasts during 187 daytime [45], and transitory leaf starch storage during nighttime [46], may contribute 188 significantly to diel growth dynamics, whereas local stem carbon reserves appear to 189 contribute only marginally to growth $[32,44]$. Despite our knowledge of such carbon-based 190 processes, diel patterns in stem growth are predictable by tree water status only [24, 47]. 191 However, the water-growth model predictions are only valid over short time periods, and 192 we need a better understanding of the described carbon processes to understand and 193 predict seasonal growth. This also highlights that much remains to be learned about the 194 relative contribution of the co-occurring and interconnected growth processes. Another 195 ambiguity is the predicted diel dynamics in phloem water flow (Figure 2E) [48, 49], which 196 are contradicted by the constant phloem flow observed in MRI studies [50]. Despite the 197 continuous attempts to refine the mechanism of turgor-driven transport of sugars from 198 leaves to sink tissues with active and passive loading strategies and a leakage-retrieval 199 process along the pathway [51], phloem transport in trees still remains poorly understood, 200 with little connection between theory, research data, and the actual behavior observed for 201 trees [52]. Thus we advocate the use of new experiments for deciphering phloem transport 202 mechanisms by combining a focus on water and carbon relationships and adding 
measurements of sugar concentrations (Figure 1). Very few data exists, because measuring

204 the pressurized living phloem is a daunting task, often hindered by induced wound

205 reactions. Therefore, new promising techniques and methods for measuring phloem sap,

206 turgor pressure, and labeled $\mathrm{CO}_{2}$ should be further explored (Box 2).

207

When the soil is dry, trees reduce leaf water loss through stomatal regulation [29],

which is directly at the cost of leaf photosynthesis and sugar loading, resulting in lower

209 sugar concentrations in the phloem (Figure 2E). The lower level of sugar loading and sugar

210 concentrations, the lower turgor, and the buffered dynamics in phloem water flow on drier

211 soil are mainly hypothetical, as are the carbon dynamics on days with well-watered soil.

212 Experimental studies have produced a number of relevant observations about these carbon

213 balance interactions within the stem on dry soils. For example, lower cell turgor affects

214 growth and maintenance respiration, resulting in lower stem $\mathrm{CO}_{2}$ effluxes and dissolved

$215 \mathrm{CO}_{2}$ in the xylem sap [37] (Figure 2F), and the formation of fewer and narrower cells

216 (Figure 3) because of the sensitivity of cell expansion and, to a lesser extent, cell division to

217 turgor $[53,54]$; woody tissue photosynthesis in xylary chloroplasts likely fulfills local 218 energetic and carbohydrate demands for repair of embolised conduits [55, 56]; and local

219 stem carbon reserves, only marginally contributing to stem growth under non-stressed 220 conditions, may become more important with drought [25]. These examples highlight the

221 inherent tight coupling of water and carbon interactions between phloem and xylem but 222 also illustrate the need for more comprehensive studies of these processes.

223 In conclusion, the fluxes, use and storage dynamics of carbon in stems remain largely

224 hypothetical, despite some understanding of the qualitative patterns. Remarkably, 225 mechanistic plant models can predict diel trends in stem diameter and, through 
226 optimization of model parameters, provide hypotheses for diel trends in sugar

227 concentrations and phloem water flow which remain to be tested. It is clear that respiration

228 rates of tree stems remain highly uncertain, as does the contribution of woody tissue

229 photosynthesis to the observed fluxes. Finally, we lack information on this shorter

230 timescale on fluxes from starch to soluble sugars, and their contribution to diel dynamics in

231 stem growth. We propose using new experiments that combine the more classic

232 measurements of water and carbon relationships with new ones (Figure 1, Box 1 and 2),

233 and emphasize the value of the integrative information obtained with diel stem diameter

234 variation dynamics, which is particularly important for providing parameter values for the

235 models. Despite their speculative nature, we consider the simulations by mechanistic plant

236 models as a promising way to develop new hypotheses. However, this approach will require

237 testing and validation with the more extensive and comprehensive data framework that

238 needs to be built for different tree species with different wood anatomical properties under

239 different water conditions.

\section{Seasonal impacts on diel stem growth}

242 Overall, mechanistic plant models capture the water dynamics and diel stem growth

243 variation $[24,29,49]$, but most of the emerging dynamics in carbon remain hypothetical. A

244 second complication is that the models cannot yet capture the gradual changes in those

245 dynamics across the growing season because of rudimentary knowledge of the coordination

246 between stem tissue formation and whole tree function (Figure 3). Seasonal stem growth as

247 measured by dendrometers reflects the formation of xylem and phloem tissue. Both tissues

248 originate from cambium cell division, but xylem mother cells divide more compared with 
249 phloem mother cells, which explains the narrower phloem than xylem ring [57]. In addition 250 to a slower growth rate, the timing of differentiation also differs, with phloem growth 251 peaking before xylem growth [58]. Although longer-term phloem information is absent

252 because sieve cells are functional for only 1-2 years and collapse afterwards, the phloem to 253 xylem ratio increases with decreasing tree vitality [59] and with the level of environmental 254 stress [60], indicating that higher priority is given to phloem tissue formation. As phloem 255 growth becomes an important fraction of total stem growth under stress conditions, which 256 affects the interpretation of stem diameter measurements, simultaneous investigation of 257 xylem and phloem is imperative for us to understand seasonal stem growth.

258 Both water and carbon will shape the seasonal growth trend as well as the resulting stem 259 anatomy and density, which, in turn, will influence xylem hydraulic conductivity and 260 cavitation vulnerability [61]. The sub-processes shaping these anatomical variations within 261 a tree ring are the rate and duration of cell enlargement and cell wall thickening [62]. 262 Interestingly, however, individual model simulations for different days predict an 263 exponential decrease in cell wall extensibility over time during the growing season [63-65], 264 which is supported by some observations [66] and is expected to result in a lower growth 265 rate potential. Here we present two alternative - but not mutually exclusive - reasons for 266 this decrease in cell wall extensibility. First, the decrease in cell wall extensibility matches 267 with the reduction in duration of cell enlargement during the growing season: from 10-20 268 days early in the growth season to less than five days later in the season $[62,67,68]$. It also 269 agrees with the production of smaller cells near the end of growth (Figure 3C). Because cell 270 size contributes more than rate of wall deposition to cell wall thickness and density [62], 271 the reduction in cell wall extensibility and, thus, cell enlargement duration, determines a 
272 great part of the ring's morphology. Under stress conditions, this becomes critical: smaller

273 cells with thicker walls and higher density will be formed, representing a compromise

274 between efficiency and safety of the conducting system (Figure 3). Under chronic stress

275 conditions [69] as well as in declining trees [70], wood with lower density and thus reduced

276 hydraulic safety has been observed, which can be explained by carbon limitation on top of

277 water limitation during cell wall formation [61]. Second, cell wall extensibility decreases

278 with increasing auxin concentrations in the cambium [71]. With the onset of shoot 279 development in spring, the production of auxin in shoots and transport downward through 280 the cambium [72] increases auxin concentrations with time and also creates auxin 281 gradients within trees [73]. It seems that high auxin concentrations accelerate cell 282 differentiation and thus reduce the period available for cell enlargement $[74,75]$, as 283 indicated by the smaller sizes of the conduit cells close to the source of auxin (in the shoots) 284 [76], or in branch junctions where two auxin flows unite [77]. The gradually increasing 285 auxin concentrations in the cambium during the growing season may thus accelerate cell 286 differentiation and reduce cell wall extensibility over time, finally resulting in the cessation 287 of growth. Here, we speculate that implementation of a mechanism of cell wall extensibility 288 versus cell age trends, which originates from the fundamental interdependencies between 289 ecophysiology and anatomy, may greatly improve plant models to simulate seasonal 290 variation in stem growth during the season. Hormonal regulation might be required for 291 simulating wood anatomy and stem growth patterns over branches [78] and whole tree 292 bodies [79].

293

\section{Concluding remarks}


295 Radial stem growth, and its ecological implications, has been studied by scientists from 296 rather separate scientific domains (anatomy, ecophysiology, dendrochronology, ecology), 297 and we still lack an integrative and tested theory to understand the causes and 298 consequences of diel stem growth patterns. Such a theory is required to understand diel 299 and seasonal growth patterns in trees and, in turn, the long-term trends in stem growth as 300 impacted by climate. One major gap in our knowledge is the quantification of diel dynamics

301 in carbon within the stem. A second major gap is how those carbon dynamics interact with

302 dynamics in water, for example, how stems coordinate embolism repair and cell turgor and,

303 in turn, stem growth. A third major gap is the poor understanding of the seasonal variation

304 in stem growth patterns. We therefore propose to combine the methodologies for studying

305 water dynamics, carbon dynamics and (anatomical) stem growth within the same study.

306 This will allow us for the first time to monitor the dynamics in carbon, water, and stem

307 anatomy and diameter simultaneously. In turn, this will enable setting crucial parameter

308 values and testing of mechanistic plant models for their emergent patterns in those

309 dynamics. We are confident that such a joint effort from separate scientific domains will

310 contribute to building and testing an integrated theory on causes of diel and seasonal

311 patterns in stem growth. Such insights are much needed for predicting the impact of a

312 changing climate on stem growth, with major implications for the well-being of trees and

313 forests under global change.

315 Acknowledgements

316 We thank R.O. Teskey for helpful comments on the original manuscript, the anonymous

317 reviewers for valuable inputs, and the Research Foundation - Flanders (FWO) (research 
318 programmes G.0319.13N and G.0941.15N granted to KS) for funding. The opinions

319 expressed in this paper were partly inspired by and are linked to the activities conducted

320 within the COST FP1106 network STReESS (Studying Tree Responses to extreme Events: a

321 SynthesiS).

322

323 References

324 1. Bonan, G.B. (2008) Forests and climate change: forcings, feedbacks, and the climate 325 benefits of forests. Science 320, 1444-1449

326 2. Beer, et al. (2010) Terrestrial gross carbon dioxide uptake: global distribution and $327 \quad$ covariation with climate. Science 329, 834-838

328 3. Luyssaert, S. et al. (2008) Old-growth forests as global carbon sinks. Nature 455, $329 \quad 213-215$

330 4. Zuidema, P.A. et al. (2013) Tropical forest and global change: filling knowledge gaps. $331 \quad$ Trends Plant Sci. 18, 413-419

332 5. Purves, D. and Pacala, S. (2008) Predictive models of forest dynamics. Science 320, $333 \quad 1452-1453$

334 6. Smith, N.G. and Dukes, J.S. (2013) Plant respiration and photosynthesis in global335 scale models: incorporating acclimation to temperature and $\mathrm{CO}_{2}$. Glob. Change Biol. $336 \quad 19,45-63$

7. Schippers, P. et al. (2015) Tree growth variation in the tropical forest: understanding 338 effects of temperature, rainfall and $\mathrm{CO}_{2}$. Glob. Change Biol. doi: 10.1111/gcb.12877 
8. van der Sleen, P. et al. (2014) No growth stimulation of tropical trees by 150 years of $\mathrm{CO}_{2}$ fertilization but water use efficiency increased. Nat. Geosci. DOI: 10.1038/NGEO2313

9. Ridge, I. (2002) Plants. Oxford University Press

10. Schulze, E.D. et al. (1985) Canopy transpiration and water fluxes in the xylem of the trunk of Larix and Picea trees - a comparison of xylem flow, porometer and cuvette measurements. Oecologia 66, 475-486

11. Goldstein, G. et al. (1998) Stem water storage and diurnal patterns of water use in tropical forest canopy trees. Plant Cell Environ. 21, 397-406

12. Steppe, K. and Lemeur, R. (2004) An experimental system for analysis of the dynamic sap-flow characteristics in young trees: results of a beech tree. Funct. Plant Biol. 31, 83-92

13. Köcher, P. et al. (2013) Stem storage in five coexisting temperate broad-leaves tree species: significance, temporal dynamics and dependence on tree functional traits. Tree Physiol. 33, 817-832

14. Schenk, H.J. et al. (2015) Nanobubbles: a new paradigm for air-seeding in xylem. Trends Plant Sci. doi:10.1016/j.tplants.2015.01.008 a dynamic model. Plant Cell Environ. 32, 10-21 coordination of stomatal control of xylem tension with hydraulic capacitance. Funct. Ecol. 23, 922-930 
17. Meinzer, F.C. et al. (2010) The blind men and the elephant: the impact of context and scale in evaluating conflicts between plant hydraulic safety and efficiency. Oecologia $164,287-296$

18. Vergeynst, L.L. et al. (2014) Cavitation: a blessing in disguise? New method to establish vulnerability curves and assess hydraulic capacitance of woody tissues. Tree Physiol. doi:10.1093/treephys/tpu056

19. Zwieniecki, M.A. and Holbrook, N.M. (2009) Confronting Maxwell's demon: biophysics of xylem embolism repair. Trends Plant Sci. 14, 530-534

20. Brodersen, C.R. and McElrone, A.J. (2013) Maintenance of xylem network transport capacity: a review of embolism repair capacity in vascular plants. Front. Plant Sci. 4, 108

21. Kozlowski, T.T. and Pallardy, S.G. (2002) Acclimation and adaptive responses of woody plants to environmental stresses. Bot. Rev. 68, 270-334

22. Sevanto, S. et al. (2011) Effects of the hydraulic coupling between xylem and phloem on diurnal phloem diameter variation. Plant Cell Environ. 34, 690-703

23. Steppe, K. et al. (2012) Could rapid diameter changes be facilitated by a variable hydraulic conductance? Plant Cell Environ. 35, 150-157

24. Steppe, K. et al. (2006) A mathematical model linking tree sap flow dynamics to daily stem diameter fluctuations and radial stem growth. Tree Physiol. 26, 257-273

25. Deslauriers, A. et al. (2014) Impact of warming and drought on carbon balance related to wood formation in black spruce. Ann. Bot. 114, 335-345 in woody plants. Plant Physiol. 126, 188-202 
27. Lockhart, J.A. (1965) An analysis of irreversible plant cell elongation. J. Theor. Biol. 8, 264-275

28. Hsiao, T.C. and Acevedo, E. (1974) Plant responses to water deficits, water-use efficiency, and drought resistance. Agr. Meteorol. 14, 59-84

29. Zweifel, R. et al. (2007) Stomatal regulation by microclimate and tree water relations

- interpreting ecophysiological field data with a hydraulic plant model. J. Exp. Bot. 58, 2113-2131

30. McDowell, N. et al. (2008) Mechanisms of plant survival and mortality during drought: why do some plants survive while others succumb to drought? New Phytol. $178,719-739$

31. Anderegg, W.R.L. et al. (2012) Linking definitions, mechanisms, and modeling of drought-induced tree death. Trends Plant Sci. 17, 693-700

32. Daudet, F.A. et al. (2005) Experimental analysis of the role of water and carbon in tree stem diameter variations. J. Exp. Bot. 56, 135-144

33. Boyer, J.S. (1968) Relationship of water potential to growth of leaves. Plant Physiol. $43,1056-1062$

34. Hsiao, T.C. et al. (1976) Stress metabolism: water stress, growth and osmotic adjustment. Philos. T. R. Soc. London Ser. B 273, 479-500

35. Ray, P.M. (1987) Principles of plant cell expansion. In: Physiology of cell expansion during plant growth (Cosgrove, D.J. and Knievel, D.P., eds), pp. 1-17, Am. Soc. Plant

405 Physiol.

36. Proseus, T.E. and Boyer, J.S. (2006) Periplasm turgor pressure controls wall 406 deposition and assembly in growing Chara corallina cells. Ann. Bot. 98, 93-105 
37. Saveyn, A. et al. (2007) Daytime depression in tree stem $\mathrm{CO}_{2}$ efflux rates: is it caused by low stem turgor pressure? Ann. Bot. 99, 477-485

38. Pantin, F. et al. (2012) Coming of leaf age: control of growth by hydraulics and metabolics during leaf ontogeny. New Phyt. 196, 349-366

39. Teskey, R.O. et al. (2008) Origin, fate and significance of $\mathrm{CO}_{2}$ in tree stems. New Phytol. 177, 17-32

40. Trumbore, S.E. et al. (2013) What's the flux? Unraveling how $\mathrm{CO}_{2}$ fluxes from trees reflect underlying physiological processes. New Phytol. 197, 353-355

41. Amthor, J.S. (1989) Respiration and crop productivity, Springer-Verlag

416

42. Steppe, K. et al. (2007) Resistance to radial $\mathrm{CO}_{2}$ diffusion contributes to betweentree variation in $\mathrm{CO}_{2}$ efflux rates of Populus deltoides stems. Funct. Plant Biol. 34, 785-792

43. Etzold, S. et al. (2013) Long-term stem $\mathrm{CO}_{2}$ concentration measurements in Norway spruce in relation to biotic and abiotic factors. New Phytol. 197, 1173-1184

44. De Schepper, V. et al. (2010) Detailed analysis of double girdling effects on stem diameter variations and sap flow in young oak trees. Environ. Exp. Bot. 68, 149-156 growth and bud development in young plants. Plant Cell Environ. 33, 1949-1958 maltose metabolism. Plant Phys. 138, 2280-2291 implications towards a growth mechanism. J. Exp. Bot. 57, 1445-1459 
48. Hölttä, T. et al. (2006) Modeling xylem and phloem water flows in trees according to cohesion theory and Münch hypothesis. Trees 20, 67-78

49. De Schepper, V. and Steppe, K. (2010) Development and verification of a water and sugar transport model using measured stem diameter variations. J. Exp. Bot. 61, 2083-2099

50. Windt, C.W. et al. (2006) MRI of long-distance water transport: a comparison of the phloem and xylem flow characteristics and dynamics in poplar, castor bean, tomato and tobacco. Plant Cell Environ. 29, 1715-1729

51. De Schepper, V. et al. (2013) Phloem transport: a review of mechanisms and controls. J. Exp. Bot. 64, 4839-4850

52. Ryan, M.G. and Asao, S. (2014) Phloem transport in trees. Tree Physiol. 34, 1-4

53. Hsiao, T.C. (1973) Plant responses to water stress. Annu. Rev. Plant Physiol. 24, 519570

54. Abe, H. et al. (2003) Temporal water deficit and wood formation in Cryptomeria japonica. Tree Physiol. 23, 859-863

55. Schmitz, N. et al. (2012) Light-dependent maintenance of hydraulic function in mangrove branches: do xylary chloroplasts play a role in embolism repair? New Phytol. 195, 40-46

56. Bloemen, J. et al. (2014) How important is woody tissue photosynthesis in poplar during drought stress? Trees DOI 10.1007/s00468-014-1132-9 Fagus sylvatica from two contrasting sites. Agr. For. Meteorol. 180, 142-151 
452

453

454

455

456

457

458

459

460

461

462

463

464

465

466

467

468

469

470

471

472

473

474

59. Gricar, J. et al. (2009) Number of cells in xylem, phloem and dormant cambium in silver fir (Abies alba), in trees of different vitality. IAWA J. 30:121-133

60. Robert, E.M.R. et al. (2011) Successive cambia: a developmental oddity or an adaptive structure? PLoS One 6:e16558

61. Balducci, L. et al. (2014) How do drought and warming influence survival and wood traits in Picea mariana saplings? J. Exp. Bot. 66, 377-389

62. Cuny, H. et al. (2014) Kinetics of tracheid development explain conifer tree-ring structure. New Phyt. 203, 1231-1241

63. Lechaudel, M. et al. (2007) An analysis of elastic and plastic fruit growth of mango in response to various assimilate supplies. Tree Physiol. 27, 219-230

64. Steppe, K. et al. (2008) Validation of a dynamic stem diameter variation model and the resulting seasonal changes in calibrated parameter values. Ecol. Model. 218, 247259

65. Hanssens, J. et al. (2012) Effect of stem age on the response of stem diameter variations to plant water status in tomato. Acta Hort. 952, 907-914

66. Cosgrove, D.J. (1993) Wall extensibility - its nature, measurement and relationship to plant-cell growth. New Phytol. 124, 1-23

67. Wodzicki, T.J. (1971) Mechanism of xylem differentiation in Pinus silvestris L. J. Exp. Bot. 22, 670-687

68. Deslauriers, A. et al. (2009) Intra-annual cambial activity and carbon availability in stem of poplar. Tree Physiol. 29, 1223-1235

69. Eilmann, B et al. (2011) Drought alters timing, quantity, and quality of wood formation in Scots pine. J. Exp. Bot. 62, 2763-2771 
475

476

477

478

479

480

481

482

483

484

485

486

487

488

489

490

491

492

493

494

495

496

70. Rosner, S et al. (2014) Wood density as a screening trait for drought sensitivity in Norway spruce. Can. J. For. Res. 44, 154-161

71. Bütenmeyer, K., et al. (1998) Auxin-induced changes in cell wall extensibility of maize roots. Planta 204, 515-519

72. Uggla, C. et al. (1996) Auxin as a positional signal in pattern formation in plants. Proc. Natl. Acad. Sci. USA 93, 9282-9286

73. Sachs, T. (1994) Self-organisation of tree form: a model for complex social systems. J. Theor. Biol. 230, 197-202

74. Aloni, R. and Zimmermann, M.H. (1983) The control of vessel size and density along the plant axis - a new hypothesis. Differentiation 24, 203-208

75. Anfodillo T. et al. (2012) Widening of xylem conduits in a conifer tree depends on the longer time of cell expansion downwards along the stem. J. Exp. Bot. 63, 837-845

76. Mencuccini, M. et al. (2007) Sanio's laws revisited. Size-dependent changes in the xylem architecture of trees. Ecol. Lett. 10, 1084-1093

77. Aloni, R. (1987) Differentiation of vascular tissues. Annu. Rev. Plant Physiol. Plant Mol. Biol. 38, 179-204

78. Kramer, E.M. and Borkowski, M.H. (2004) Wood grain patterns at branch junctions: modelling and implications. Trees 18, 493-500

79. Sterck, F.J. (2005) Woody tree architecture. In: Plant architecture and its manipulations (Turnbull, C.G.N. ed.), pp. 210-237, Blackwell

80. Smith, D.M., Allen, S.J. (1996) Measurement of sap flow in plant stems. J. Exp. Bot. 47, $1833-1844$ 
81. Vandegehuchte, M.W. and Steppe, K. (2013) Sap flux density measurement methods: working principles and applicability. Funct. Plant Biol. 40, 213-223

82. Hao, G.Y. et al. (2013) Investigating xylem embolism formation, refilling and water storage in tree trunks using frequency domain reflectometry. J. Exp. Bot. 64, 23212332

83. Vandegehuchte, M.W. and Steppe, K. (2012) Sapflow+: a four needle heat-pulse sap flow sensor enabling non-empirical sap flux density and water content measurements. New Phytol. 196: 306-317

506

84. Edwards, W.R.N. and Jarvis, P.G. (1982) Relations between water content, potential and permeability in stems of conifers. Plant Cell Environ 5, 271-277

85. McGuire, M.A. and Teskey, R.O. (2002) Microelectrode technique for in situ 508 measurement of carbon dioxide concentrations in xylem sap of trees. Tree Physiol. $22,807-811$

86. Gould, N. et al. (2005) Phloem hydrostatic pressure relates to solute loading rate: a direct test of the Münch hypothesis. Funct. Plant Biol. 32, 1019-1026 $248,165-172$

88. Epron, D. et al. (2012) Pulse-labelling trees to study carbon allocation dynamics: a review of methods, current knowledge and future prospects. Tree Physiol. 32, 776798

518

89. Rossi, S. et al. (2006) THREPHOR: a new tool for sampling microcores from tree 519 
521 Integrative experiments with new technology and methods (Figure 1) can capture diel 522 water dynamics within tree stem across the season under field conditions.

\section{Sap flow sensor}

524 Sap flow sensors measure sap flow rate $\left(\mathrm{g} \mathrm{h}^{-1}\right)$ or sap flux density $\left(\mathrm{cm}^{3} \mathrm{~cm}^{-2} \mathrm{~h}^{-1}\right)$, and allows

525 quantification of whole-tree water use without altering the transpiration conditions. Many

526 methods have been developed (see reviews by [80, 81]), and these use heat to sense sap

527 movement in the stem xylem. Accurate estimates of sap flow are critical when assessing

528 water transport and storage dynamics, but also when estimating xylem $\mathrm{CO}_{2}$ transport in

529 trees, or for understanding diel dynamics in stem $\mathrm{CO}_{2}$ concentration and stem $\mathrm{CO}_{2}$ efflux.

\section{Sapwood water content sensor}

531 Sapwood water content sensors measure sapwood water content $\left(\mathrm{m}^{3} \mathrm{~m}^{-3}\right.$ or $\mathrm{kg}$ water $(\mathrm{kg}$ 532 dry weight)-1), which is considered as critical component in the whole-tree water balance

533 because of its direct link to changes in internal water storage. These techniques for 534 assessing sapwood water content, such as frequency domain reflectometry [82] and

535 Sapflow+ sensors [83] are new and promising, but still under further development.

\section{Stem psychrometer}

537 Stem psychrometers measure stem water potential (MPa), which is a robust and direct 538 indicator of the plant water status, and expresses the tension (negative values) along the

539 continuous water column in the xylem, typically pulling the water upwards in the tree.

540 Concurrent measurements of stem water potential and sapwood water content would allow

541 us to explore, for the first time, in situ the diel dynamics in hydraulic capacitance (C [ $\mathrm{kg} \mathrm{m}^{-3}$ 
$542 \mathrm{MPa}^{-1}$ ), quantified as the amount of water that can be released from living tissues into the

543 transpiration stream for a unit decrease in water potential [84].

\section{Acoustic emission sensor}

545 Acoustic emission sensors measure acoustic emissions (AE), which are linked to cavitation 546 events, when gas nanobubbles expand and form embolisms [14], typically triggered by high

547 xylem water tensions. Cumulative AEs may be used to estimate relative loss of hydraulic 548 conductivity in the xylem [18].

\section{Point dendrometer and linear variable displacement transducer}

550 Point dendrometers and linear variable displacement transducers measure variations in 551 stem diameter $(\mu \mathrm{m})$ at high temporal resolution (e.g. 10 minute intervals). The sensor 552 signal simultaneously displays the integrative result of: (1) irreversible radial xylem and 553 phloem growth, (2) reversible shrinking and swelling of the living stem cells due to changes 554 in internally stored water, (3) contraction and expansion of dead conducting xylem 555 elements due to the increase and relaxation of internal tensions, and (4) thermal expansion 556 and contraction of the stem [32]. When interpreting stem diameter measurements, it is

557 important to consider that phloem tissue degrades over time with the inherent information 558 disappearing over time. Tracking variations in stem diameter with and without phloem 559 tissue has been suggested as a promising approach to study xylem-phloem interactions and 560 phloem turgor without damage [22].

561

562 Box 2. Material list for quantifying carbon dynamics within stems

\section{Solid state non dispersive infrared (NDIR) sensor}


564 Solid state non dispersive infrared (NDIR) sensors measure the $\mathrm{CO}_{2}$ concentration of gas

565 (\%) in holes drilled into the stem (high concentrations, range $<1$ to over 26\%; [39]). Using

566 Henry's law, it is possible to convert measured $\mathrm{CO}_{2}$ concentrations in the gaseous phase

$567\left(\left[\mathrm{CO}_{2}\right], \%\right)$ to the amount of $\mathrm{CO}_{2}$ dissolved in xylem sap ([CO $\left.{ }_{2}^{*}\right], \mathrm{mol} \mathrm{l}^{-1}$, [85]).

\section{Stem cuvette connected to infrared gas analyzer (IRGA)}

569 A stem cuvette connected to an infrared gas analyzer (IRGA) measures the net flux of $\mathrm{CO}_{2}$

570 diffusing out of the stem section into the atmosphere $\left(\mu \mathrm{mol} \mathrm{m}^{-2} \mathrm{~s}^{-1}\right)$. The $\mathrm{CO}_{2}$ is produced by

571 the living cells of xylem, cambium and phloem, or is imported in the transpiration stream

572 (Figure 2). Stem cuvettes are typically dark to exclude local woody tissue photosynthesis.

\section{Aphid stylet}

574 Aphid stylets are used to collect phloem sap for analysis of osmotic pressure and sap sugar

575 concentration, and when a cell pressure probe is glued to an exuding stylet of an aphid

576 feeding from the phloem, turgor pressure can be monitored [86, 87].

\section{Pulse labeling of trees with stable or radioactive carbon isotopes}

578 The carbon isotope (atoms of an element with the same atomic number, but with different

579 atomic masses) content of assimilated carbon is artificially altered using stable $\left({ }^{13} \mathrm{C}\right)$ or 580 radioactive $\left({ }^{14} \mathrm{C}\right.$ and $\left.{ }^{11} \mathrm{C}\right) \mathrm{CO}_{2}$ as short pulses over longer periods, and the fate of labeled $\mathrm{CO}_{2}$

581 into the tree and its release to the atmosphere is traced to quantify carbon allocation in 582 trees and assess its role in stem growth. Methods and associated challenges are reviewed in $583[88]$.

584 Micro-borer 
585 The micro-borer is a tool used to extract stem micro-cores from the tree stem to investigate 586 cambial activity, which cannot be directly observed or measured from outside the stem.

587 Repeated sampling of newly formed xylem and phloem allows quantifying the temporal 588 dynamics of stem anatomy and formation during the growing season (Figure 3). To 589 minimize damage, stem samples are extracted as small cores with a Trephor micro-borer 590 [89]. (For instruction movie, see:

591 http://www.wageningenur.nl/en/Expertise-Services/Chair-groups/Environmental-

592 Sciences/Forest-Ecology-and-Forest-Management-Group/Show/Microcore-Processing593 instruction-film-launched.htm) 


\section{Figure captions}

595 Figure 1. Schematic of important processes, fluxes and pools of water and carbon inside a 596 stem segment of a tree (right): (1) sap flow in the xylem (or transpiration stream), 597 transporting part of the dissolved $\mathrm{CO}_{2}$ (7d); (2) phloem sap flow, transporting sugars and 598 dissolved $\mathrm{CO}_{2}$; (3) radial exchange of internally stored water between living cells in xylem 599 and phloem, and the transpiration stream; (4) hydraulic capacitance, defining the capacity 600 of living cells to store water and release it into the transpiration stream; (5) growth 601 respiration; (6) maintenance respiration; (7) diffusion of $\mathrm{CO}_{2}$ out of the stem from phloem 602 (a), cambium (b) and xylem ray cells (c); or imported in xylem sap (d); (8) $\mathrm{CO}_{2}$ diffusing 603 into the transpiration stream from phloem (a), cambium (b) or xylem ray cells (c); (9) axial $604 \mathrm{CO}_{2}$ diffusion along air-filled spaces in the wood; (10) $\mathrm{CO}_{2}$ fixation by woody tissue 605 photosynthesis, which can utilize $\mathrm{CO}_{2}$ from all four sources (a, b, c, d) above; (11) carbon 606 pool, which consists of recently assimilated sugars transported in the phloem (2), locally 607 refixed $\mathrm{CO}_{2}$ in photosynthetic tissue (10), and local starch reserves (modified after $[39,40]$ ). 608 Details of the technology and methods used for quantifying the diel dynamics in water, 609 carbon and stem growth (left) can be found in Box 1 and 2.

611 Figure 2. Diel patterns in water and carbon dynamics for a fully exposed canopy tree 612 during a sunny day in unstressed conditions with ample soil water reserves (left), and a 613 sunny day in dry soil conditions (right). We distinguish between well-established patterns 614 and more speculative patterns in green and red, respectively. Measured variations in stem

615 diameter (A) integrate diel dynamics in water (B, C, D) and carbon (E, F). (a) Stem diameter 616 variation measured on xylem and phloem (see Figure 1). (B) The line shows the sap flow in 
617 the sapwood, and the dots show the acoustic emission signals reflecting cavitation events,

618 whenever gas nanobubbles expand and form embolisms. (C) Water content (positive

619 values) and stem water potential (negative values). (D) Turgor pressure in the dividing

620 cambium and expanding cells, and wall-yielding threshold value. (E) Sugar loading in the

621 phloem, water flow rate in the phloem, and sugar concentration (dashed line indicates

622 model simulation and green dots indicate measurements). (F) Two possible patterns for

623 stem $\mathrm{CO}_{2}$ efflux (see explanation in the text), and dissolved $\mathrm{CO}_{2}$ in the xylem sap. Details of

624 the technology and methods used to measure the diel patterns in water, carbon and stem

625 growth (green) can be found in Box 1 and 2 and are illustrated in Figure 1. The scale of the

$626 y$-axis is virtual, covering the range of values of each variable.

627

628 Figure 3. Seasonal growth patterns in expanding tree rings of Populus $\times$ canadensis trees in 629 a temperate environment, for a tree on a soil with ample water reserves during the whole 630 growing season (blue lines in A, B) and another tree exposed to dry soil conditions in the 631 middle of the growing season (red lines in A, B). Stem samples of the micro-sections color 632 reddish (after adding safranin) when cell walls with lignin had established, or color blue 633 (after adding astrablue) in the absence of lignin and when still expanding. (A) Seasonal 634 patterns in radial stem growth as measured with point dendrometers (without the diel 635 fluctuation). Snapshots of possible co-occurring wood formation processes at some key 636 moments during the growing season are shown. Wood formation resulted from cell division 637 in the cambial zone $(\mathrm{Cz})$ and cell enlargement (ENL), whereas cell wall thickening and 638 lignification (CWT) happened afterwards to form secondary cell walls, ultimately shaping 639 tree-ring width and anatomy. At the same time, the cambial zone $(\mathrm{Cz})$ also produces sieve 
640 cells of phloem $(\mathrm{Ph})$. During spring, when cambium division just started, the first rows of 641 enlarging cells appeared which eventually differentiated into vessels (Mv), fibers (f) or 642 parenchyma (p). Finally, the cambium stopped producing new cells in both trees. During 643 dry conditions, a lower number of smaller fibers (Ef) and smaller vessels (Ev) were formed 644 due to the impacts of a lower turgor on cell division and cell expansion. As a result, tree-ring 645 width and anatomy reflect plastics adjustments to best fit the environmental conditions 646 when the stem was formed $(B, C)$ : the drought-exposed tree showed a narrower tree ring 647 with higher wood density during drought, which generally reflects a lower hydraulic 648 conductivity but a safer transport system.

649 


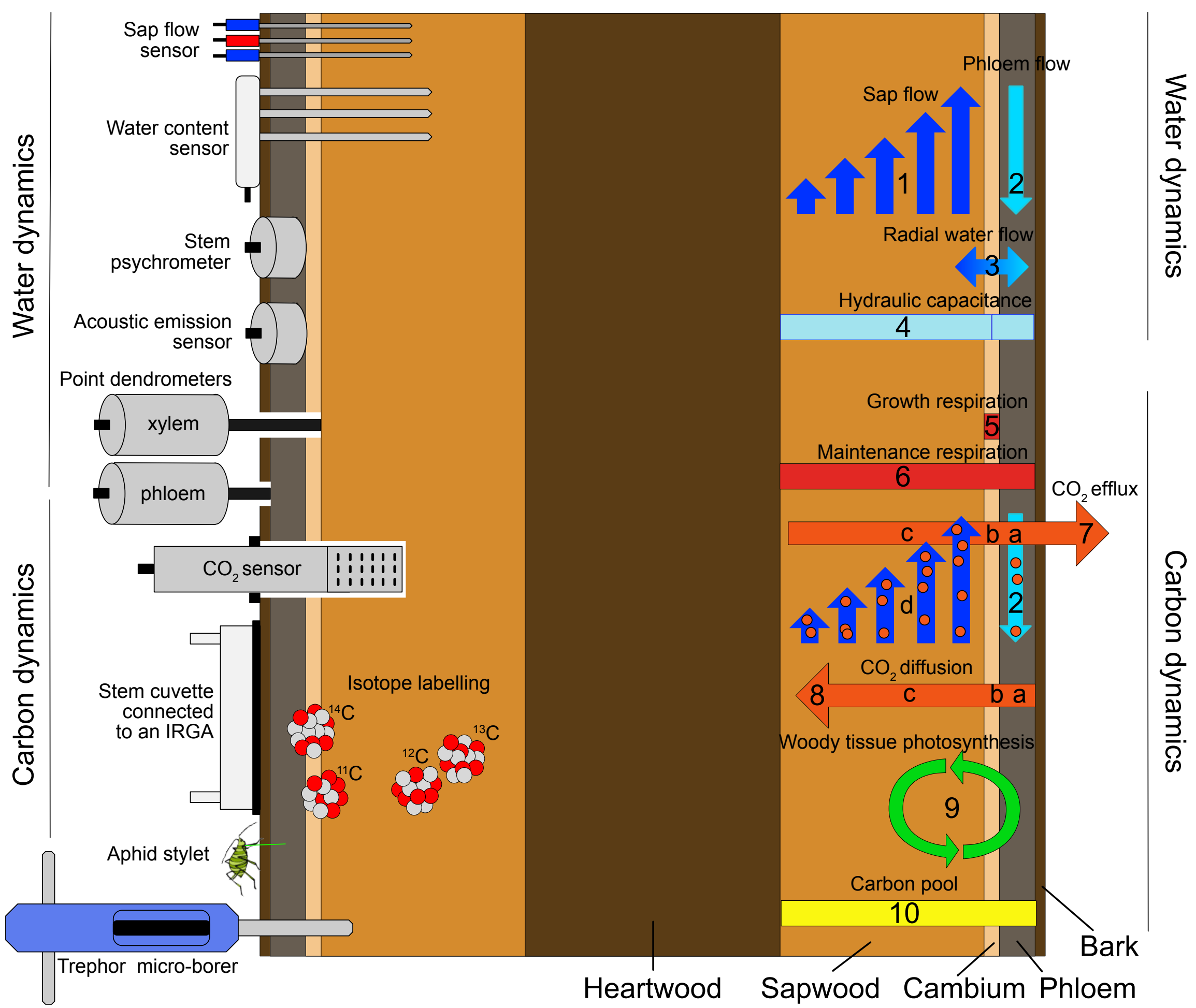



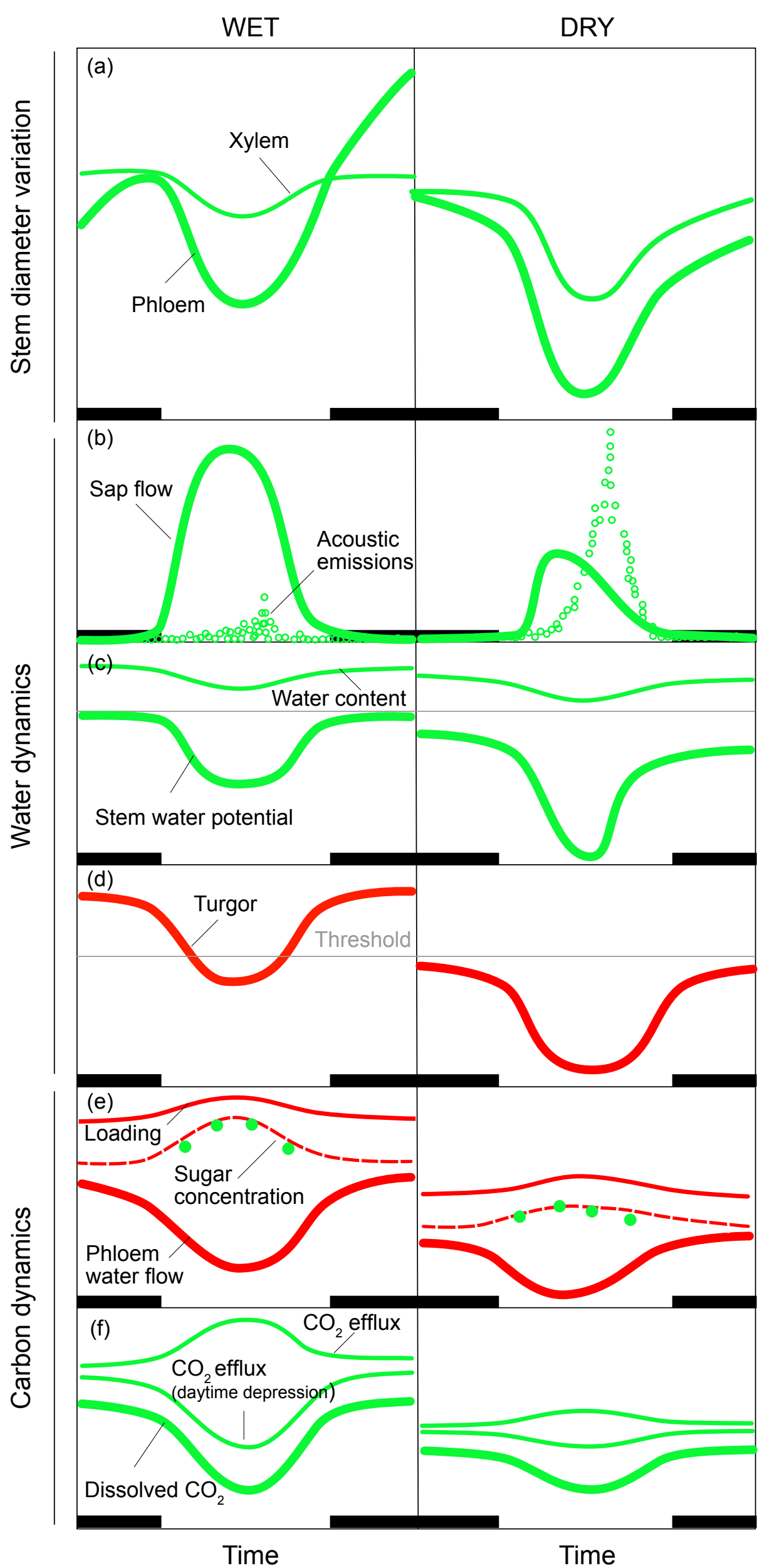

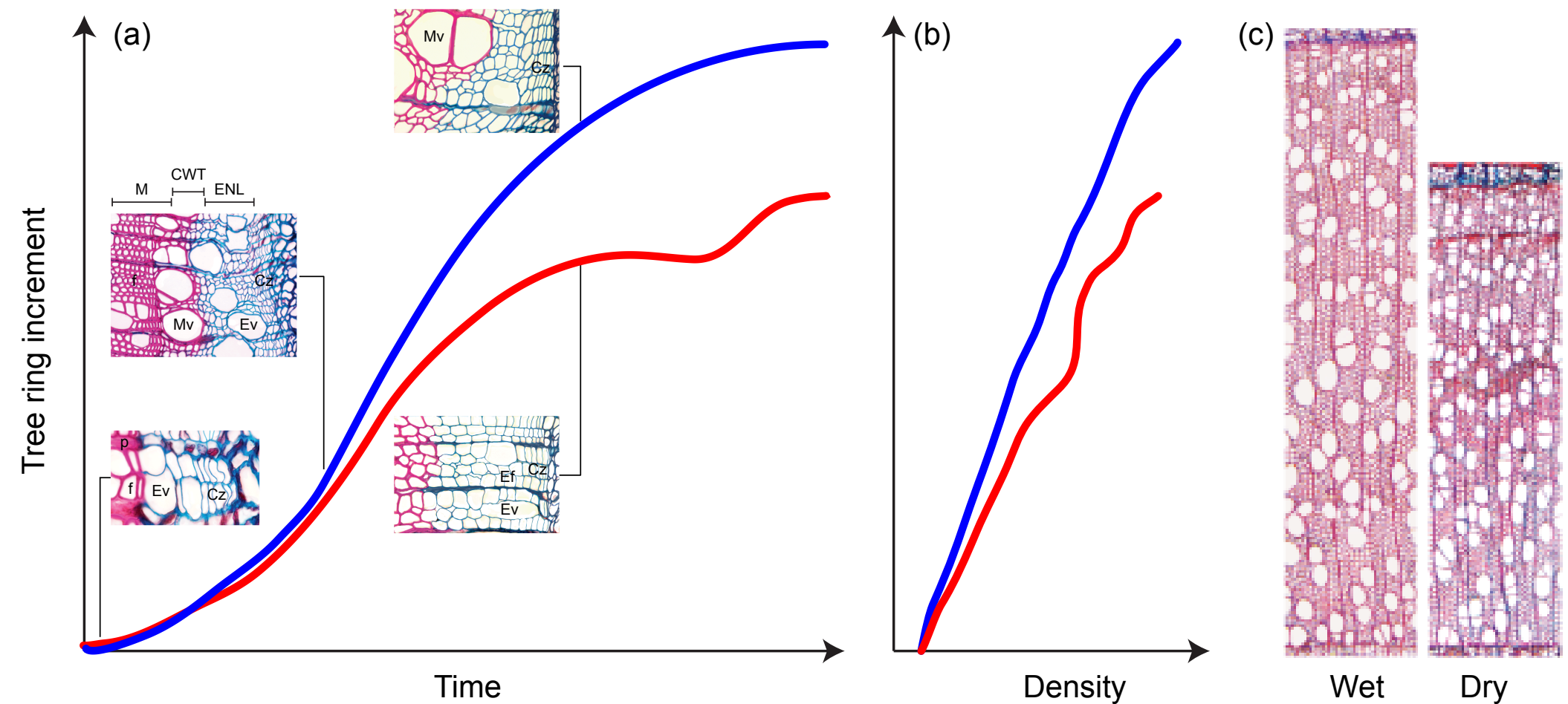